\title{
The location of descending fibres to sympathetic neurons supplying the eye and sudomotor neurons supplying the head and neck
}

\author{
PW NATHAN, MARION C SMITH* \\ From the National Hospital for Nervous Diseases, Queen Square, London, UK
}

SUMMARY Evidence is given of the location in man of the fibres going to the sympathetic neurons of the lateral horn that supply the intrinsic and extrinsic muscles of the eye and the sweat glands of the head and neck. For the region of the pons and medulla, the evidence is abstracted from the literature. For the cervical spinal cord, the evidence is from our cases of anterolateral cordotomy. In the medulla, thrombosis of the artery of the fossette laterale destroys the fibres; this locates the fibres in the posterolateral retro-olivary area. But not all fibres to the sudomotor neurons lie there: some run elsewhere, though they probably remain ipsilateral. In the cervical cord, the fibres supplying the sympathetic neurons of the intrinsic and extrinsic muscles of the eye run near the posterior angle of the anterior horn. Most of the fibres supplying the sudomotor neurons lie in the same region, though some lie outside this area but on the same side of the cord.

This paper presents evidence on the location within the human spinal cord of the pathways running from the hypothalamus to the preganglionic sympathetic neurons supplying intrinsic and extrinsic muscles of the eye and the sweat glands of the head and neck. The location of these pathways above the spinal cord is abstracted from the literature; our evidence concerns the location within the cervical cord.

Evidence that occlusion of the superior cerebellar artery causes ptosis, miosis and absence of sweating in the ipsilateral side of the face was presented by Freeman and Jaffe ${ }^{1}$ and Luhan and Pollack. ${ }^{2}$ Luhan and Pollack's fig 3 is given here as fig 1 and their fig 1 is given as fig 2 . In the case illustrated here by fig 1 , there was softening in the distribution of the right superior cerebellar artery. The region involved was the caudal mesencephalic tegmentum and adjacent region of the pons. In the case illustrated by fig 2 , the left superior cerebellar artery "appeared like a thick white string." There was an area of softening in the tegmentum of the rostral pons, just beneath the locus coeruleus. Thus these authors showed that a fairly small lesion in

*Present Address: Radcliffe Infirmary, Oxford.

Address for reprint requests: Dr PW Nathan, the National Hospital for Nervous Diseases, Queen Sq, London WCIN 3BG, UK

Received 22 March 1985 and in revised form 21 May 1985. Accepted 28 May 1985 the tegmentum between the caudal midbrain and the rostral pons destroyed the oculosympathetic fibres. This lesion extends laterally to the periphery of the pons; it is posterior to the medial lemniscus; its anterior limit is on a line with the anterior border of the periaqueductal gray. This lesion also destroys the spinothalamic tract.

There is ample evidence that at more caudal levels, occlusion of the posterior inferior cerebellar artery disturbs these sympathetic functions. It is known at this hospital that when Gowers was consulted about patients who had had a stroke and was told that there was loss of pain and thermal sensibility, he asked only one question: on which side is the small pupil; and he would then give the diagnosis of posterior inferior cerebellar thrombosis on the side of the small pupil.

Winther ${ }^{3}$ tried to distinguish the course in the medulla of the different descending fibres to sympathetic preganglionic neurons with different functions. This material consisted of his own two cases with post mortem evidence and cases reported in the literature. He concluded that all the fibres were in the lateral part of the reticular formation "situated between the posterior border of the nucleus ambiguus and the descending root of the trigeminal, probably nearer the former." He thought the evidence hinted that fibres supplying the sudomotor and vasomotor neurons were anterior to the oculosympathetic fibres; and that the fibres supplying the sudomotor and vasomotor 


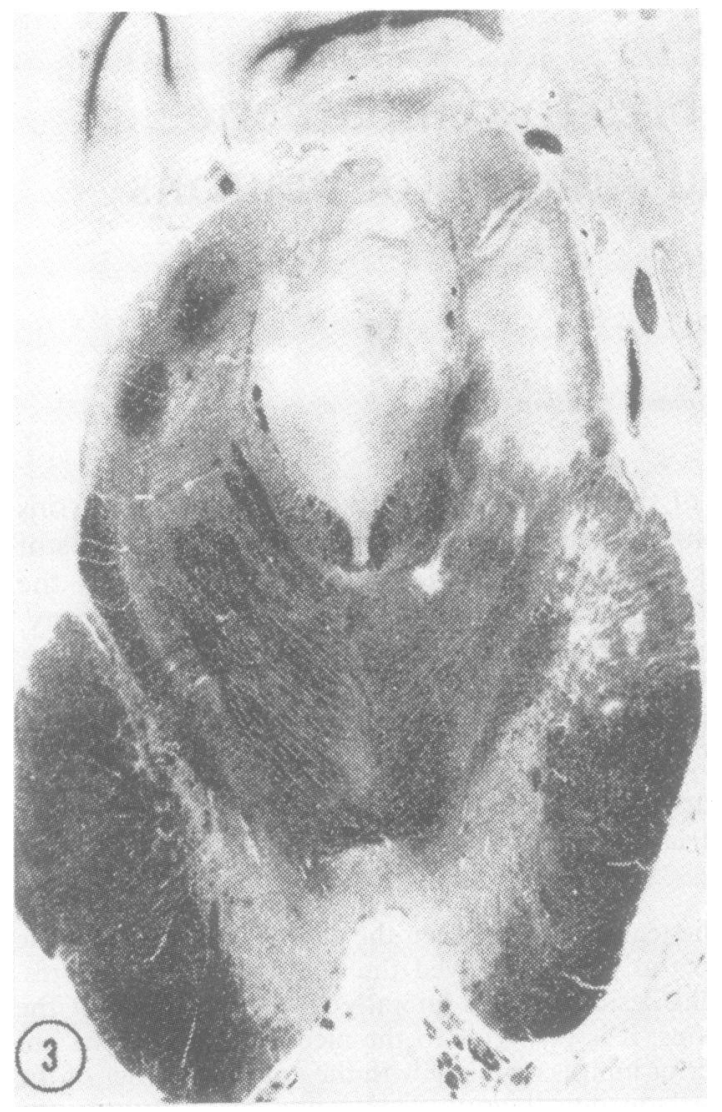

Fig 1 A reproduction of fig 3 from Luhan and Pollack. ${ }^{2}$ The section is through the caudal midbrain. It shows the region of softening in the tegmentum due to occlusion of the superior cerebellar artery.

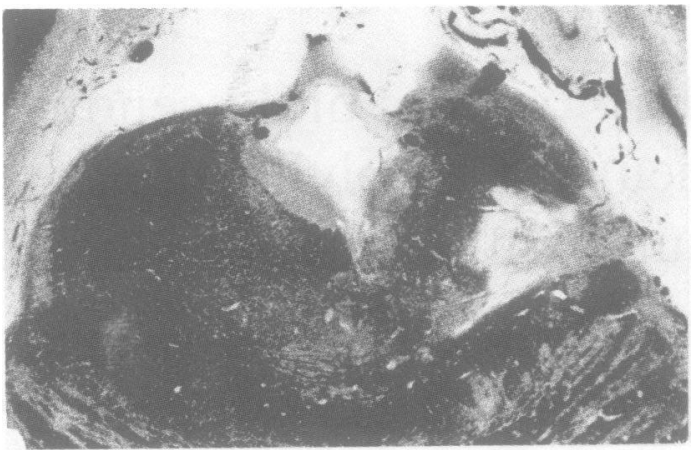

Fig 2 A reproduction of fig 1 from Luhan and Pollack, ${ }^{2}$ showing the region of softening in another case due to occlusion of the superior cerebellar artery. The section is through the rostral pontomesencephalic tegmentum at the level of the trochlear nerve. In both these cases, the descending fibres to sympathetic neurons supplying the eye, head and neck are destroyed by the lesions.

neurons to the trunk and limbs lay further anteriorly, on a transverse section, just posterior to the spinothalamic fibres.

Foerster et $\mathrm{l}^{4}$ concluded from their own material iv of tumours of the midbrain, pons and medulla ow $\vec{\infty}$ longata and from similar cases in the literature tha $v$

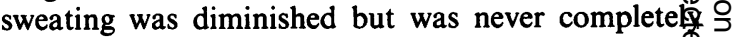
absent on the side of the Horner's syndrome. From $\rightarrow$ their cases of cervical cordotomy they concluded the the fibres for sweating of the whole body ran in thro anterior and anterolateral columns; this conclusiog was based on the observation that sweating was usur. ally disturbed after anterolateral cordotomies.

The most important paper on this subject is that of $\%$ List and Peet. ${ }^{5}$ They investigated 18 patients though

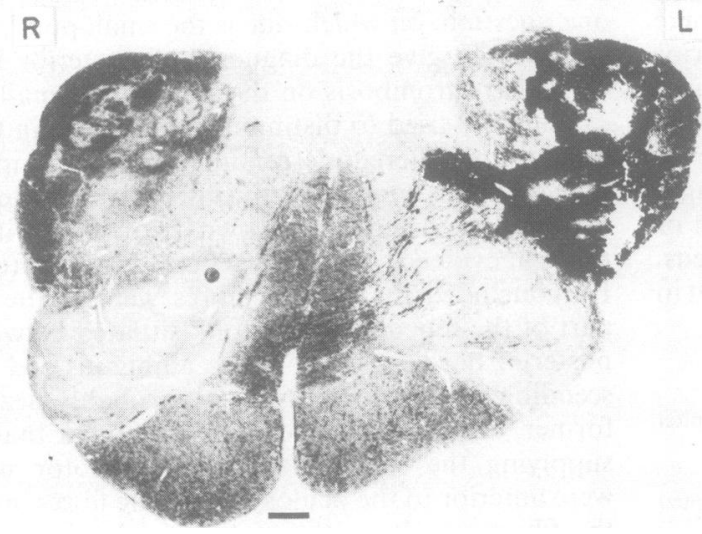

Fig 3 The region of softening due to occlusion of the posterior inferior cerebellar artery. The descending fibres to the sympathetic neurons supplying the eye and the majority of fibres to the sudomotor neurons supplying the head and neck are destroyed by this lesion. 


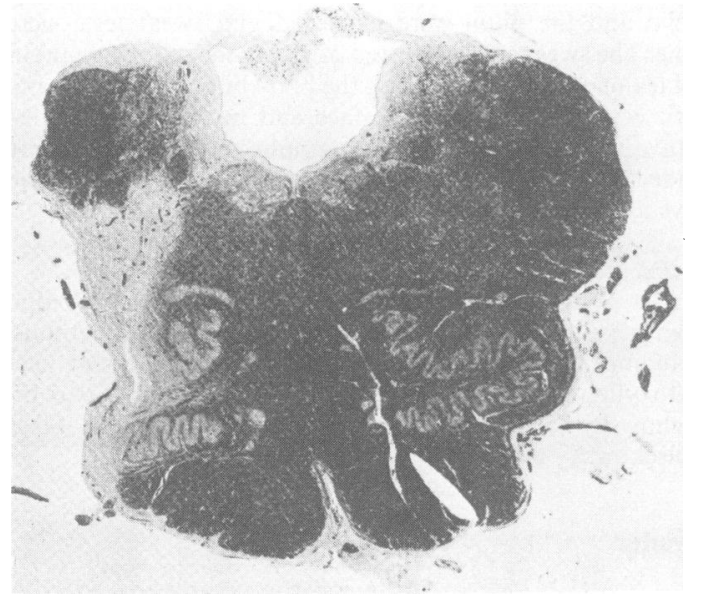

Fig 4 A reproduction of fig 10 from Foix and Hillemand. ${ }^{6}$ It shows the region of softening due to occlusion of the "artère de la fossette laterale". The descending fibres to the sympathetic neurons supplying the eye and the majority of fibres to the sudomotor neurons supplying the head and neck are destroyed by this lesion.

unfortunately they could obtain a post mortem examination in only one of them. This was a case of thrombosis of the posterior inferior cerebellar artery. We have studied three cases of thrombosis of the posterior inferior cerebellar artery in detail, but unfortunately no post mortem evidence could be obtained. We therefore show in a fourth case the typical extent of this lesion (fig 3 ). The clinical evidence in these cases is largely similar to that of List and Peet's Case 11, in which there was post mortem evidence of a posterior inferior cerebellar artery thrombosis. In all cases the fibres to the orbit were involved. But sweating was affected differently. In our three cases there was no ipsilateral sweating of the head and neck, but in 2 of the 3 , there was sweating on both sides of the forehead. List and Peet's patient had sweating too on both sides of the forehead, and bilaterally on the neck, with some sweating on the face on the side of the lesion.

List and Peet concluded from their total evidence that the descending pathways to the neurons supplying the eye and those supplying sudomotor neurons to the face were "in the dorsolateral 'retro-olivary' area in the medulla". They thought that the fibres to the sudomotor neurons descended to the thoracic cord in the lateral reticulospinal tract.

List and Peet's Case 10 is important; for although there was no post mortem confirmation, the lesion is most likely to have been a thrombosis of the artery of the fossette laterale of the medulla. This was described by Foix and Hillemand. ${ }^{67}$ The area of softening from occlusion of this artery (fig 10 of their paper) is shown as fig 4 here. The lesion in this case affects only the lateral part of the medulla and therefore shows that the relevant fibres lie within a smaller region than can be deduced from cases of thrombosis of the posterior inferior cerebellar artery.

From these cases it is concluded that in the medulla the fibres supplying the neurons running to the eye are in the posterolateral retro-olivary region. The fibres supplying the sudomotor neurons are not completely confined to this region, but it is probable that they run ipsilaterally.

The one case with post mortem examination reported by List and Peet forms the evidence on which the account given in the textbooks by Crosby et $a l^{8}$ and Schneider et $a l^{9}$ is based. List and Peet interpreted their cases largely on evidence from species other than man. This was the material in Kappers et $a l^{10}$ and the studies by Papez ${ }^{11}$ of the reticulospinal tracts in the cat.

With regard to the course of these fibres within the cervical cord, List and Peet's Case 11, with histological confirmation, showed a large group of degenerating fibres in the first cervical segment lateral to the posterior horn, reaching the periphery of the cord and extending anteriorly to a transverse plane passing just anterior to the central canal. Further caudally, this group of fibres lay medial to the posterior spinocerebellar tract and formed a curve running towards the anterior horn.

In the monkey, Kerr and Brown ${ }^{12}$ located the sympathetic pupillomotor fibres in the cervical cord in "the most peripheral part of the anterolateral funiculus, from the dentate insertion area to the vicinity of the ventral root exit zone". They concluded that all the fibres lay quite superficially, near the surface of the cord. Further experimental work undertaken by Loewy et $\mathrm{l}^{13}$ led to the same conclusion. The pupillodilator pathway lay "dorsolateral to the pyramidal tract" in the medulla. And they reasonably added that "In the human medulla, the inferior olivary nucleus is more developed than in the cat and this would tend to shift the positon of the pupillodilator fibres to a more dorsolateral position". They found that in the cervical cord of the cat these descending fibres lay in a superficial position in the lateral funiculus near the insertion zone of the dentate ligament. They stated that their axon degeneration studies confirmed these results.

\section{Patients}

The material for this investigation consists of eight patients having a unilateral, and one patient having a bilateral, cervical anterolateral cordotomy; these patients came to necropsy and the location of the lesions was ascertained. One further 


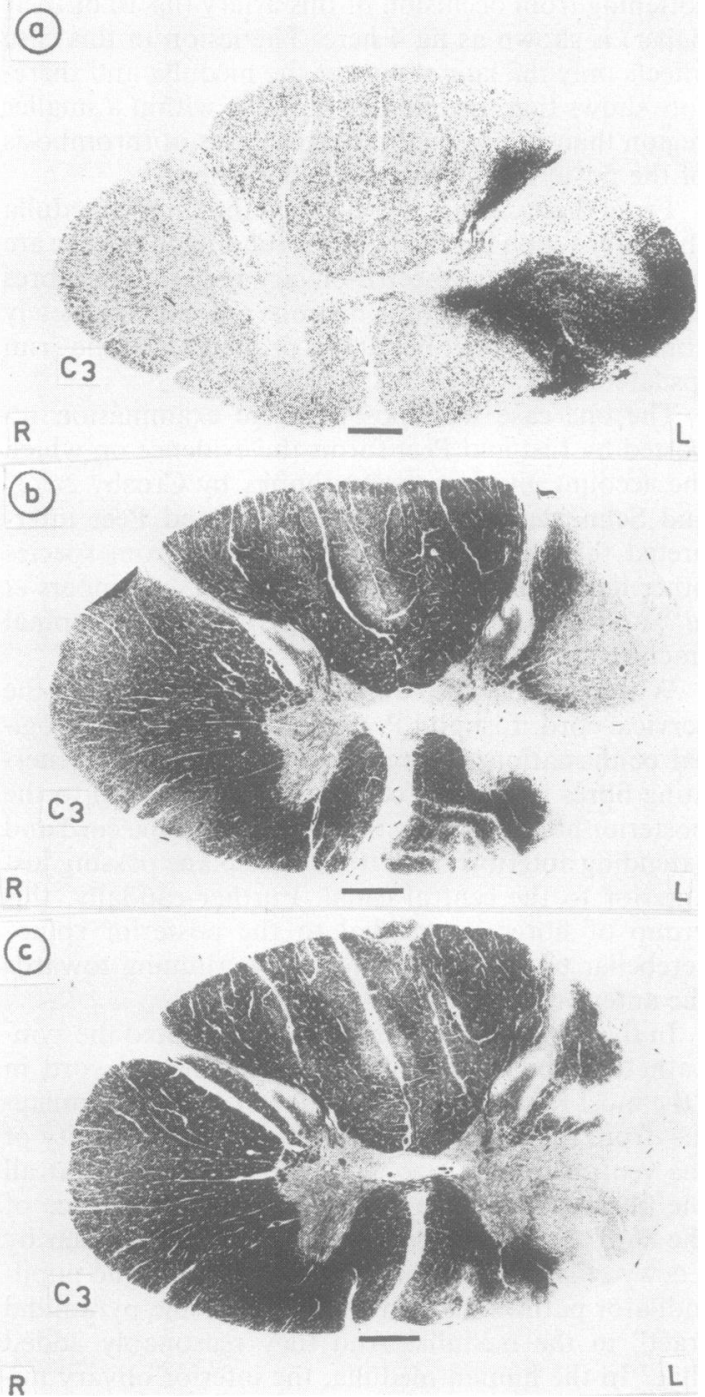

Fig 5 Lesions in two patients which transected fibres to the oculosympathetic neurons. (a) Case 37. Marchi preparation. (b) and (c) Case 110. Lesions due to two percutaneous cordotomies. Weigert-Pal preparations. Bar $=1 \mathrm{~mm}$.

case is presented in whom no necropsy has been obtained as the patient is still alive. These patients were selected from our total material as they provided evidence on the location of the fibres going to sympathetic neurons supplying the intrinsic and extrinsic muscles of the eye and to sudomotor neurons supplying the face and neck.

\section{Methods}

Clinical

Before and after the operation, the position of the upper eyelid and the pupil were inspected and sweat tests were done. The sweat tests consisted of giving the patient a pint of hot tea or coffee and covering the body but not the head and neck with heat cradles. The face and neck were sprinkled with quinizarin powder. Photographs and drawings were made. The post-operative sweat test was carried out 10-40 days after the operation.

\section{Histological}

Blocks of the cervical cord were embedded in celloidin. Transverse sections were prepared by a variety of methods, including Weigert Pal, Loyez, phosphotungstic acid haematoxylin, Marchi, Glees, Erikson and Marsland, Gros Bielschowsky and Starega's ${ }^{14}$ modification of the Gros Bielschowsky method.

\section{Results}

The cases are grouped to show the evidence of the location of the fibres at two levels, from the 1st to the 4th cervical segments and at the 5th and 6th cervical segments.

Location of fibres supplying sympathetic pupillodilator neurons and neurons to upper eyelid

In the two patients whose lesions are shown in fig $5 \mathrm{a}_{\text {, }}$ $\mathrm{b}$ and $\mathrm{c}$ there was lid-drop and miosis on the side of the lesion. The rather large lesion shown in fig $5 \mathrm{~b}$ an $\$$ c was due to two separate percutaneous cordotomieste It is deduced that in these patients the fibres going to the oculosympathetic neurons of the thoracic cord were transected.

In the three patients of whom the lesions are show in fig $6 \mathrm{a}, \mathrm{b}$ and $\mathrm{c}$, there was no Horner's syndrome. is deduced that in these patients the fibres were not transected. In the patient whose lesion is shown in fig $6 \mathrm{~d}$, after the cordotomy there was slight diminution in the size of the ipsilateral pupil, but it was not very small and there was no dropping of the eyelid. After a few weeks the size of the pupil returned to normal. It is proposed that in this case the surgical lesion involved the fibres minimally.

On the right side of fig 7 are shown diagrammatically the three cases in which the descending fibres were not involved and on the left the two cases in which they were definitely involved. Superimposition of the areas shown by the two sides of the diagram shows a small region not transected in the non-involved cases and transected in the definitely involved cases; in the diagram, this area has been marked in black. Although this is shown as a small area, it is probable that in fact it is somewhat larger than this and that the relevant fibres are scattered a short distance around this region. Thus these fibres lie in the deeper white matter, close to and just posterior to the posterior angle of the anterior horn. They are entirely unilateral. 

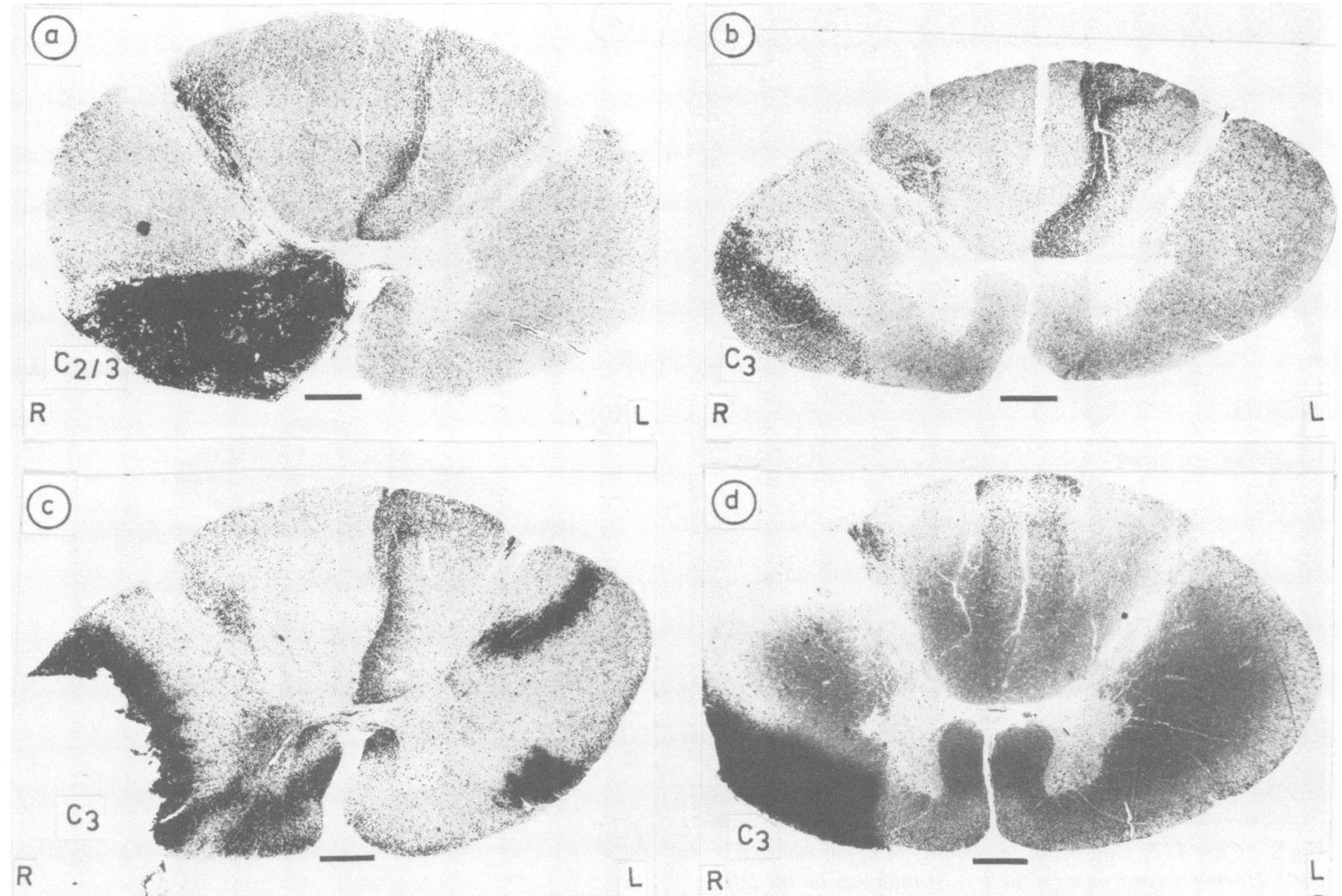

Fig 6 Lesions in three patients which did not transect fibres to oculosympathetic neurons. (a) Case 44, (b) Case 35, (c) Case 105. (d) Lesion in one patient, Case 20, in which the fibres were minimally involved. Marchi preparations. Bar $=1 \mathrm{~mm}$.

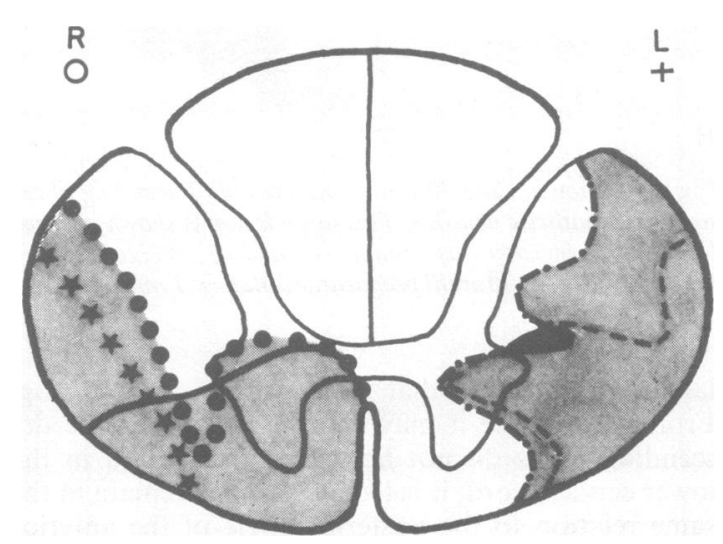

Fig 7 Diagram showing lesions on the left side that definitely involved the fibres to the oculosympathetic neurons and on the right lesions that did not involve these fibres. The small region common to the involved cases and not involved in the other cases is shown in black.
Location of fibres to the sudomotor neurons supplying the face and neck; upper cervical cord

The following case of percutaneous cordotomy at the 1st cervical segment is described; although there was no necropsy, it shows that all the fibres for the orbit can be transected without dividing all the fibres to the sudomotor neurons. Following the cordotomy, $\mathrm{Mr} \mathbf{M}$ (Case 112) had anhidrosis on the left face and neck and over most of the forehead. But, as can be seen from fig 8 , on the upper forehead and front of the head, there was sweating on the same side as the Horner's syndrome. This sweating started $2 \mathrm{~min}$ after sweating on the right side; the test was carried out twice, with the same result. The point in presenting this case (without post mortem confirmation of the site of the lesion) is to show that the sudomotor fibres to the face and neck were involved in the lesion together with those to the orbit and pupil, but fibres to the sudomotor neurons to the upper forehead and front of the head were not all divided.

In the patient of whom the lesion is shown in fig 9 , 


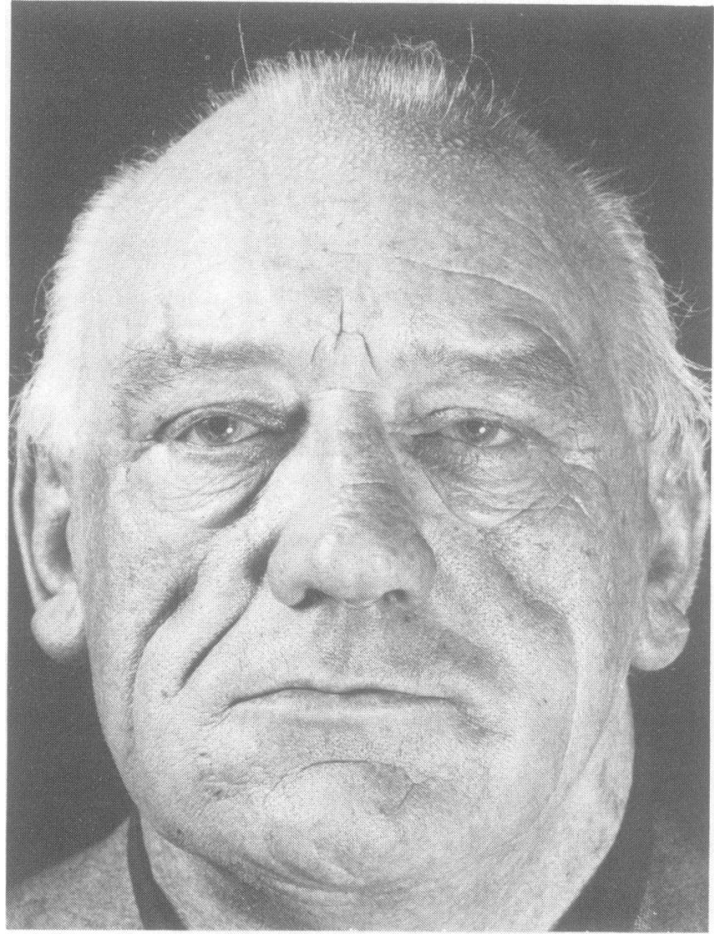

Fig 8 Case 112: Unilateral cordotomy in upper cervical cord, Horner's syndrome on the left. Anhidrosis on the left face and neck and most of the forehead; on the upper forehead and front of the head, sweating is present.

there was ipsilateral absence of sweating in the face, head and neck (as well as a Horner's syndrome). This large lesion is shown in three sections at different levels as it was oblique to the long axis of the cord. This lesion is too large to help in the localisation of the relevant fibres, but it shows that the descending fibres to the sudomotor neurons are all unilateral in the cervical cord.

In fig 10 are shown the cords of the patients in whom there was bilateral and normal sweating. Fig 11 is a diagram with cross-hatching on the left showing the lesions that did involve descending fibres to sudomotor neurons and on the right showing the lesion that did not involve these fibres. A comparison of the areas on the two sides shows that the fibres lie in the region of the posterior angle of the anterior horn and it is likely that they are in the same position as the descending fibres to the neurons running to the eye shown in fig 7 .

Lower cervical cord

In fig 12 are shown bilateral lesions at $\mathrm{C} 5$ and a uni-

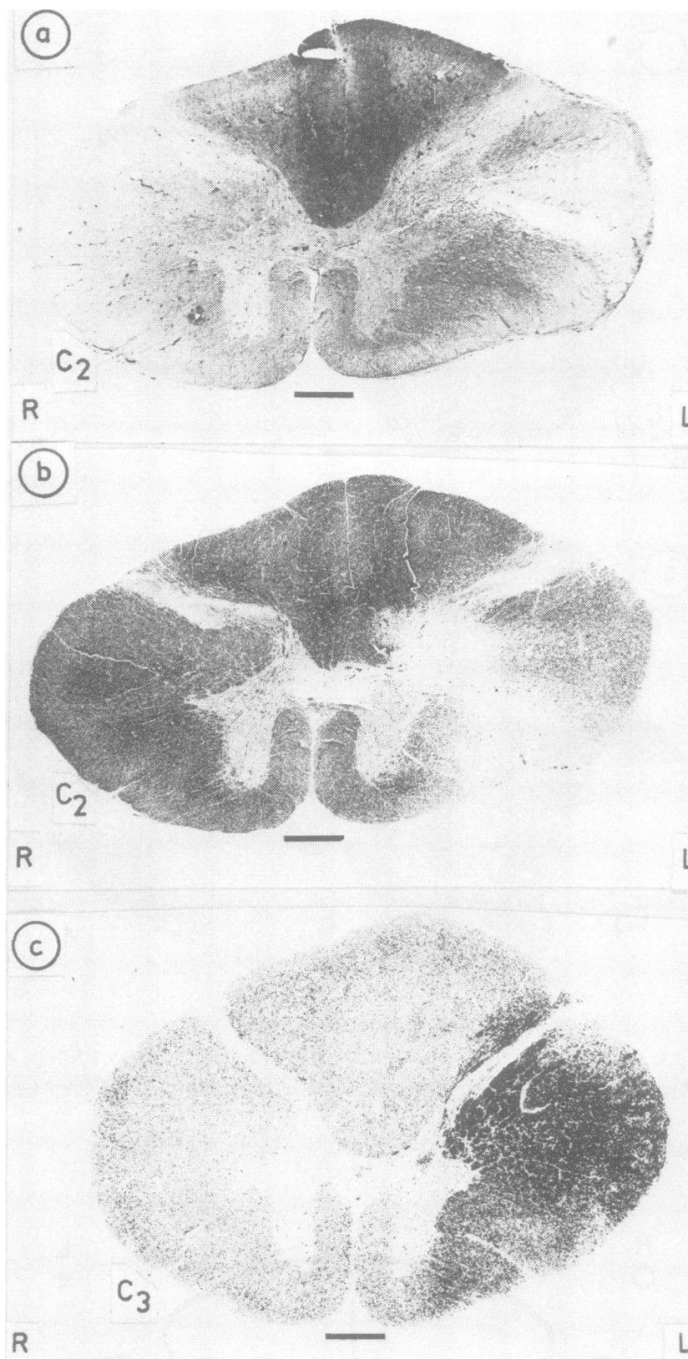

Fig 9 Lesion in Case 80 that transected all descending fibre to the sympathetic neurons. This large lesion is shown at three levels as the incision was oblique. (a) and (b) Weigert-Pal preparations. (c) Marchi preparation. Bar $=1 \mathrm{~mm}$.

lateral lesion at $\mathrm{C} 6$ that had no effect on sweating. From these three it may be concluded that the descending fibres do not lie within this region in the lower cervical cord; it is likely that they remain in the same relation to the posterior angle of the anterior horn as they did further cranially.

\section{Discussion}

From the material presented here it is concluded that 

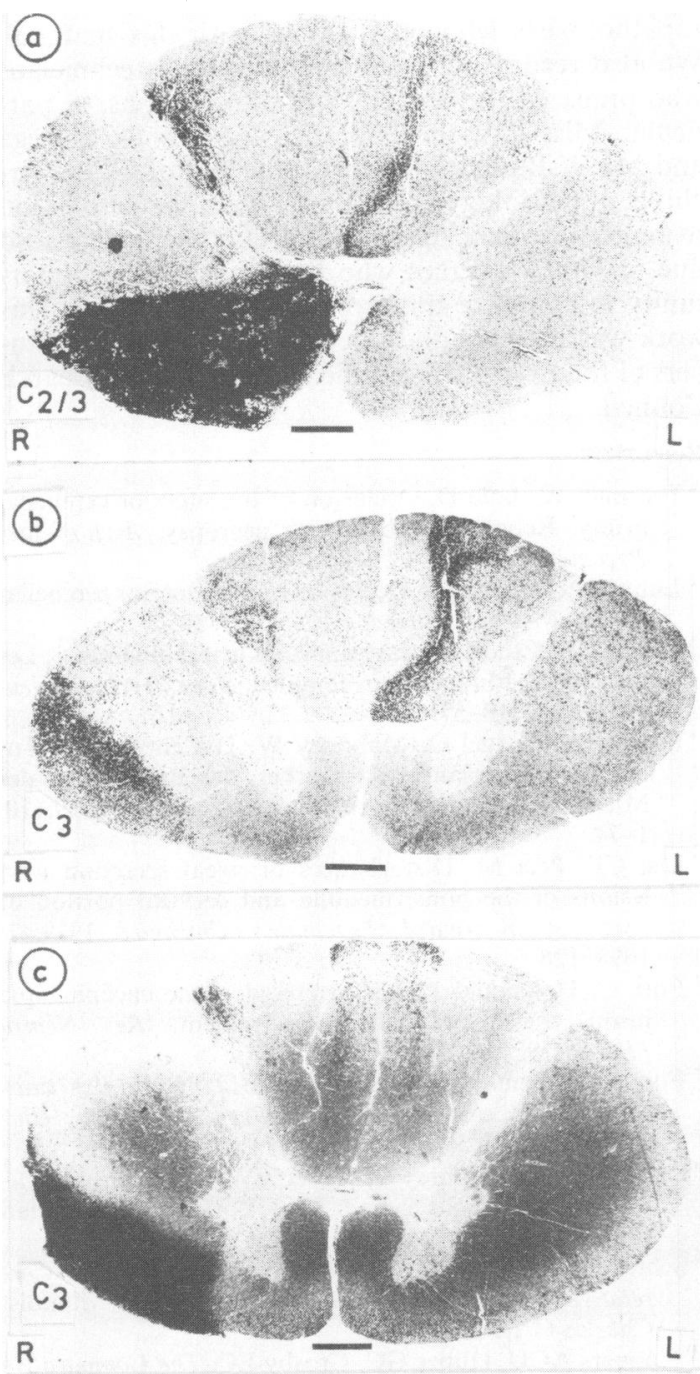

Fig 10 Lesions in three patients (a) Case 44, (b) Case 35, (c) Case 20 that did not transect fibres descending to the sudomotor neurons. Marchi preparations. Bar $=1 \mathrm{~mm}$.

the fibres supplying the sympathetic neurons of the intermedio-lateral column of the grey matter of the upper thoracic cord lie in the upper cervical cord close to the posterior angle of the anterior horn; and that in all probability they are in the same position in the lower cervical cord. They run entirely unilaterally. The fibres supplying the sudomotor neurons run in the same area. Some of these must lie outside this area, though they all run ipsilaterally. As they are all unilateral in the cervical cord, it is probable that cranial to the cord the fibres that run outside the main

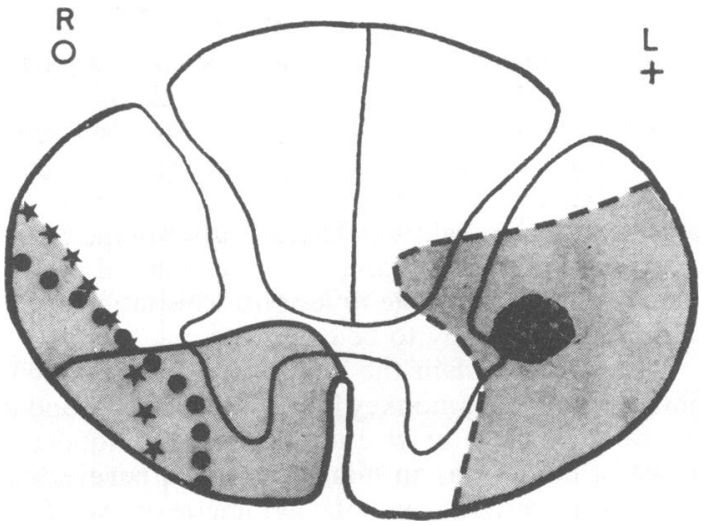

Fig 11 Diagram showing lesion on the left that involved fibres to the sudomotor neurons and on the right lesions that did not involve these fibres. The dotted area indicates the region within which it is presumed that the sudomotor fibres run.
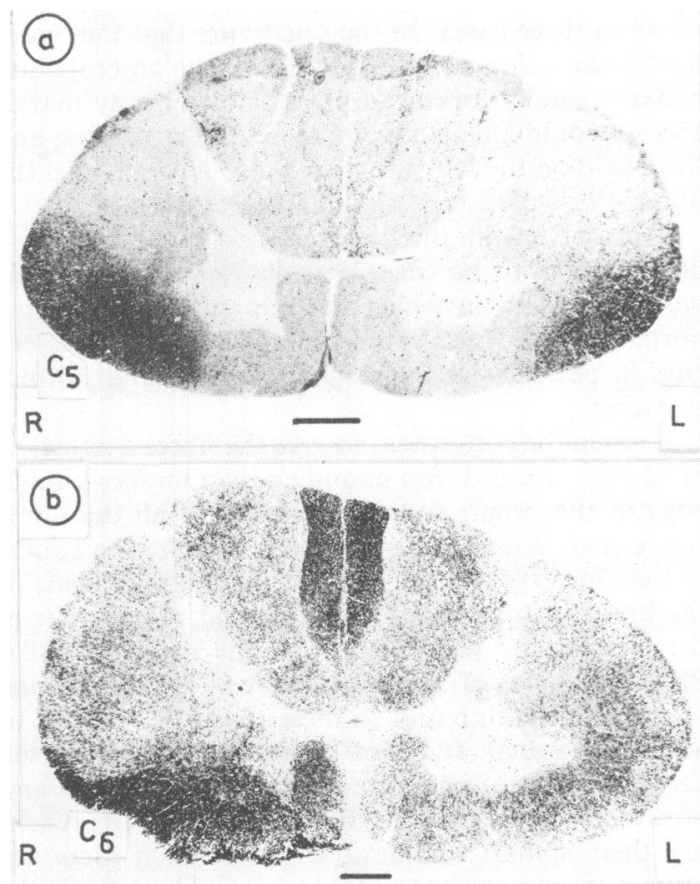

Fig 12 Lesions in two patients (a) Case 19 and (b) Case 91, in which the lesions did not transect the fibres going to the sudomotor neurons. Marchi preparations. Bar $=1 \mathrm{~mm}$. 
location are also running ipsilaterally.

Lesions due to other conditions, such as syringomyelia and syringobulbia, can damage the fibres going to neurons supplying the pupils without damaging those going to the rest of the orbit. Such material shows that the descending fibres to these two groups of neurons have slightly different courses in the brainstem, medulla and cord; or else that they are differentially susceptible to lesions. This latter explanation is more likely to be correct.

We cannot explain the different location of these fibres found in the monkey by Kerr and Brown and in the cat by Loewy et al. Indeed, from our total evidence of cordotomy in man, we cannot believe that any lesion interfering with the millimetre or two of the periphery of the cord would have any clinical manifestations. Further, our case, illustrated in fig $6 c$, alone shows that the descending fibres in man do not lie where Kerr et al located them in the cat and monkey. For this region of the cord had been completely destroyed and there was no disturbance of sympathetic function.

Confirmation of the location of the fibres supplying sympathetic neurons going to the eye was provided by the cases operated upon by Ischia et al. ${ }^{15}$ In all their cases of bilateral percutaneous cervical cordotomy, there was a Horner's syndrome. They obtained a necropsy in three cases. In the one figure that they published, the lesion on the right side in the anterolateral column would appear to extend to the grey matter and so would have divided the descending fibres; and the lesion on the left side would also have divided the fibres.

From reviewing the literature and our cases, there do not seem to be cases with lesions of the central nervous system in which there is anhidrosis with a normally innervated orbit; although the opposite occurs in patients with miosis and ptosis and normal sweating.

It would be convenient to give the fibres a name, as Schneider $e t$ al did. But naming a tract implies knowledge of the origin and terminations of all the fibres concerned. What we have done is to trace the course of the fibres. We do not know if the origin of some of the fibres is in the hypothalamus and of others is in the tectum, the tegmentum and the lower medulla. Probably some of the fibres have a synapse in the reticular formation and so these might be referred to as reticulospinal. It is not known how many of the descending fibres pass directly to the spinal cord and how many have relays in the brainstem before reaching their spinal terminations. Until such facts are known, giving names to these various fibres would be premature and even misleading.

We are grateful to all the neurosurgeons and neu- ropathologists who provided us with this material. We also record our appreciation to the technicians who prepared the sections and photographs, in particular Miss Patricia Deacon, Miss Ursula Starega and Mr W Bessant. We thank the Editor of the Archives of neurology and Dr JA Luhan for permission to reproduce their figs 1 and 3. Our thanks are also due to Dr JT Hughes who has given us the opportunity to complete this work in his laboratory. This work was mainly done when the authors were members of the External Scientific Staff, Medical Research Council.

\section{References}

${ }^{1}$ Freeman W, Jaffe D. Occlusion of the superior cerebellar artery. Report of a case with necropsy. Arch Neurol Psychiatr (Chicago) 1941;46:115-26.

${ }^{2}$ Luhan JA, Pollack SL. Occlusion of the superior cerebellar artery. Neurol (Minneap) 1953;3:77-89.

${ }^{3}$ Winther K. Etude sur les syndromes hemibulbaires. 1. Les voies sympathiques dans le bulbe. Acta Psychiatr Neurol 1932;7:719-57.

${ }^{4}$ Foerster O, Gagel O, Mahoney W. Die encephalen Tumoren des Verlängerten Markes, der Brücke und des Mittelhirns. Arch Psychiatr Nervenkrank 1939;110: 1-74.

${ }^{5}$ List CF, Peet M. Disturbances of sweat secretion wit lesions of the pons, medulla and cervical portion of cord. Arch Neurol Psychiatr (Chicago) 1939;420 1098-126.

${ }^{6}$ Foix $C$, Hillemand $P$. Les artères de l'axe encéphalique jusqu' au diencéphale inclusivement. Rev Neuroł $\mathbb{D}$ (Paris) 1925;32(ii):705-39.

${ }^{7}$ Foix C, Hillemand P. Contribution à l'étude des rane ollissements protubérantiels. Rev Med Rev Chr 1926;43:287-305.

${ }^{8}$ Crosby EA, Humphrey T, Lauer EW. Correlative Anatomy of the Nervous System. New York: The Macmillan Co., 1962.

${ }^{9}$ Schneider RC, Kahn EA, Crosby EA, Taren JA. Correlative Neurosurgery. 3rd ed. Springfield, Illinois: Charles C Thomas, 1982.

${ }^{10}$ Kappers ACU, Huber GC, Crosby EC. The Comparative Anatomy of the Nervous System of Vertebrates, including Man. New York: The Macmillan Co., 1936.

${ }^{11}$ Papez JW. Reticulospinal tracts in the cat. J Comp Neurol 1926;41:365-99.

${ }^{12}$ Kerr FWL, Brown JA. Pupillomotor pathways in the spinal cord. Arch Neurol 1964;10:262-70.

${ }^{13}$ Loewy AD, Araujo JC, Kerr FWL. Pupillodilator pathways in the brain stem of the cat: anatomical and electrophysiological identification of a central autonomic pathway. Brain Res 1973;60:65-91.

${ }^{14}$ Starega U. A silver impregnation technique for normal axons in the human central nervous system for celloidin and epon sections, with substitutes for soft tap water. Stain Technol 1984;60:1-8.

${ }^{15}$ Ischia S, Luzzani A, Ischia A, Maffezzoli G. Bilateral percutaneous cervical cordotomy: immediate and longterm results in 36 patients with neoplastic disease. $J$ Neurol Neurosurg Psychiatry 1984;47:141-7. 